\title{
New horizons in pulmonary arterial hypertension therapies
}

\author{
Nazzareno Galiè ${ }^{1}$ and Ardeschir-Hossein Ghofrani ${ }^{2,3}$
}

Affiliations: 'Dept of Experimental, Diagnostic and Specialty Medicine - DIMES, Bologna University Hospital, Bologna, Italy. ${ }^{2}$ University of Giessen and Marburg Lung Center (UGMLC), Giessen, Germany. ${ }^{3}$ Dept of Medicine, Imperial College London, London, UK.

Correspondence: N. Galiè, Dept of Experimental, Diagnostic and Specialty Medicine - DIMES, Bologna University Hospital, Via Massarenti 9, Bologna 40138, Italy. E-mail: nazzareno.galieđunibo.it

ABSTRACT Pulmonary arterial hypertension (PAH) is a fatal disease associated with vasoconstriction and vascular remodelling. There are three well-known pathways that contribute to the pathogenesis of PAH: endothelin, nitric oxide and prostacyclin. Treatments targeting these pathways are well established in clinical practice, such as endothelin receptor antagonists, phosphodiesterase type-5 inhibitors and epoprostenol. New treatments have been developed with the aim of improving efficacy and ease of administration of therapies targeting these three established pathways, and several of these new treatments have recently undergone phase III investigation. Ongoing pre-clinical studies are also beginning to uncover other mechanisms that play a role in the complex pathobiology of PAH. These include genetic targets, transcription factors and signalling pathways. The discovery of new treatment targets may change the landscape of PAH therapy in the future. Herein, we present some of the promising future treatments and interesting new therapeutic targets.

0

@ERSpublications

$\mathrm{PAH}$-specific therapies have improved outcomes, but PAH remains progressive and fatal; new drugs are in development http://ow.ly/pPHGl

\section{Introduction}

Pulmonary arterial hypertension (PAH) is a disease of the small pulmonary arteries that is, in part, due to vasoconstriction and remodelling of the vascular wall [1]. These processes contribute to a characteristic progressive increase in pulmonary vascular resistance (PVR) and subsequent effects on the right ventricle that will eventually lead to death [2].

The pathogenesis of PAH is complex and many factors have been identified or proposed as contributing to this vasoconstriction and vascular remodelling (fig. 1). These fall into several key, but somewhat interrelated and overlapping, categories as follows: vasoactive factors, calcium signalling molecules, inflammatory mediators, growth factors, bone morphogenetic protein receptor 2 (BMPR2) mutations and metabolic dysfunction.

Over the past two decades, three major pathways (the prostacyclin, endothelin and nitric oxide (NO) pathways) have been established as being key to the development and progression of PAH [1, 3]. These pathways have been targeted by $\mathrm{PAH}$-specific therapies that fall into three drug classes: prostacyclin analogues, endothelin receptor antagonists (ERA) and phosphodiesterase-5 inhibitors (PDE-5i). In registration trials, drugs in these classes have been universally shown to improve exercise capacity and haemodynamics of patients with PAH (table 1) [4-17]. In addition, some of these drugs were shown to

Received: Sept 132013 | Accepted after revision: Oct 122013

Conflict of interest: Disclosures can be found alongside the online version of this article at err.ersjournals.com

Provenance: Publication of this peer-reviewed article was supported by Actelion Pharmaceuticals Ltd, Switzerland (principal sponsor, European Respiratory Review issue 130).

Copyright OERS 2013. ERR articles are open access and distributed under the terms of the Creative Commons Attribution Non-Commercial Licence 3.0. 


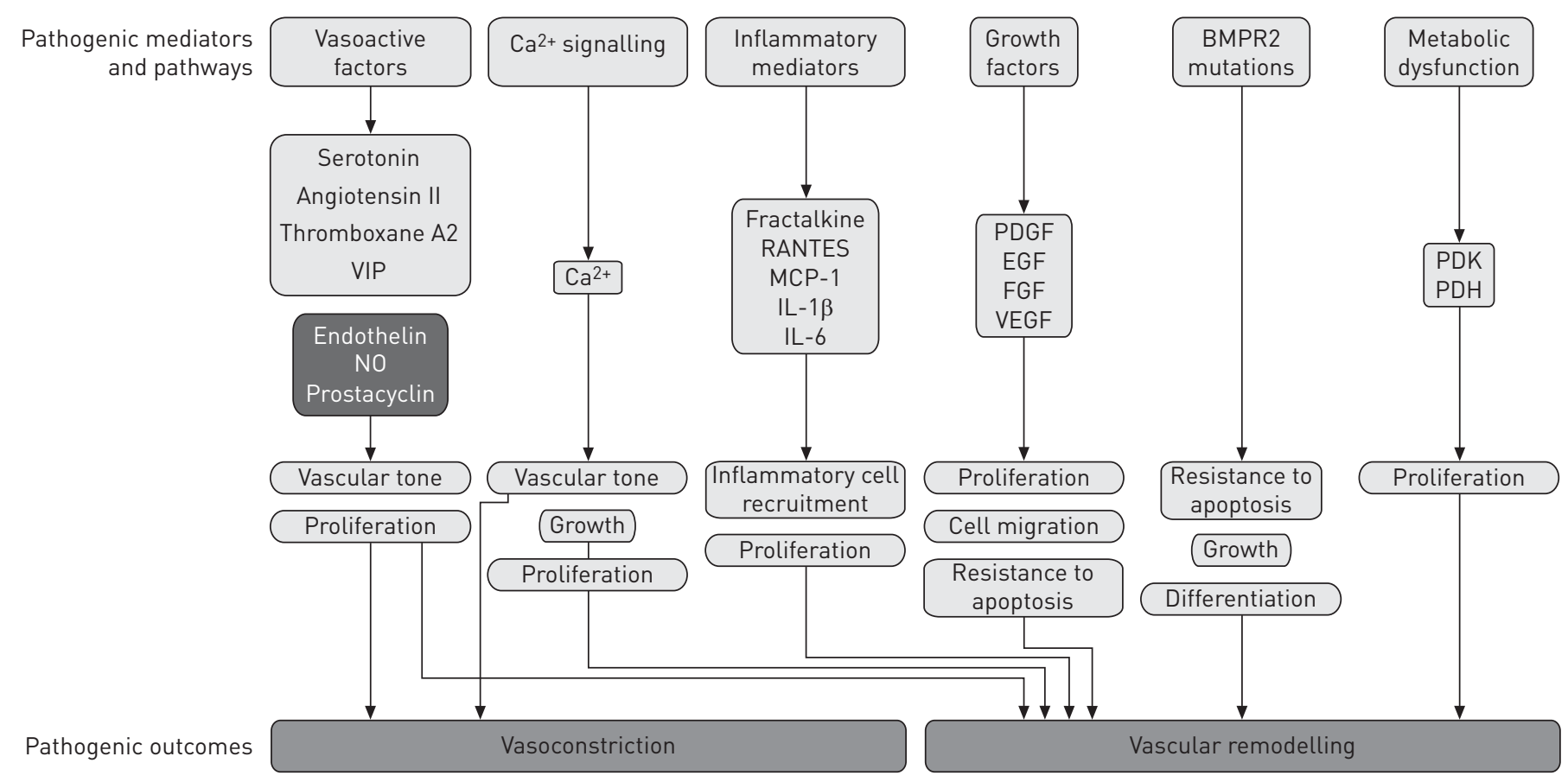

FIGURE 1 Established and putative mediators and pathways involved in the pathogenesis of pulmonary arterial hypertension. BMPR2: bone morphogenetic peptide receptor 2; VIP: vasoactive intestinal peptide; NO: nitric oxide; RANTES: regulated on activation, normal T-cell expressed and secreted; MCP: monocyte chemoattractant protein; IL: interleukin; PDGF: platelet-derived growth factor; EGF: epidermal growth factor; FGF: fibroblast growth factor; VEGF: vascular epidermal growth factor; PDK: pyruvate dehydrogenase kinase; PDH: pyruvate dehydrogenase.

improve symptoms, survival, functional class and time to clinical worsening. The use of these agents in clinical practice has been shown to be associated with improvements in outcome for patients with PAH compared with historical data; however, there remains room for improvement [18-20].

One strategy for improving the therapeutic options available for patients has been to develop new and improved drugs that target the established prostacyclin, endothelin and NO pathways. There are new drugs acting on each of these pathways that are currently, or have recently, undergone phase III development, which are described is this review.

Continual research into the molecular mechanisms of PAH has led to the discovery of new putative pathways and so opened up the possibility of new drug targets (fig. 2). Drugs acting on these pathways that are already in clinical development as potential treatments for PAH are described within this review. There are many more agents acting on these newly elucidated pathways that have the potential to become treatments for PAH. The most promising of these compounds will be discussed later. This review also touches on drugs developed for $\mathrm{PAH}$ that have been investigated in another form of pulmonary hypertension $(\mathrm{PH})$, namely chronic thromboembolic pulmonary hypertension (CTEPH).

\section{New drugs}

Within the past 5 years, there have been several phase III registration trials for new PAH-specific drugs, namely macitentan, selexipag, riociguat and imatinib. Macitentan is a new and improved agent of the ERA drug class that has recently been approved by the US Food and Drug Administration for the treatment of PAH patients. Selexipag, an oral agonist of the IP prostanoid receptor, opens up a new class of PAH-specific drugs acting on the prostacyclin pathway. Riociguat, a guanlyate cyclase stimulator, is representative of a new class of drugs with a new mechanism of action targeting the NO pathway. Imatinib, a tyrosine kinase inhibitor, is the first non-vasoactive drug to go into phase III clinical development and targets pathways solely related to vascular remodelling.

\section{Macitentan}

Macitentan is a novel dual ERA with sustained receptor binding [21], and optimised physicochemical properties leading to enhanced tissue penetration [22]. Studies have shown that macitentan has a limited drug-drug interaction profile $[23,24]$. It also has no significant inhibitory effects on hepatic bile salt transport [25] and, therefore, has the potential for a favourable liver safety profile [26]. 
TABLE 1 Efficacy parameters tested in historical registration trials of drugs approved for use in pulmonary arterial hypertension

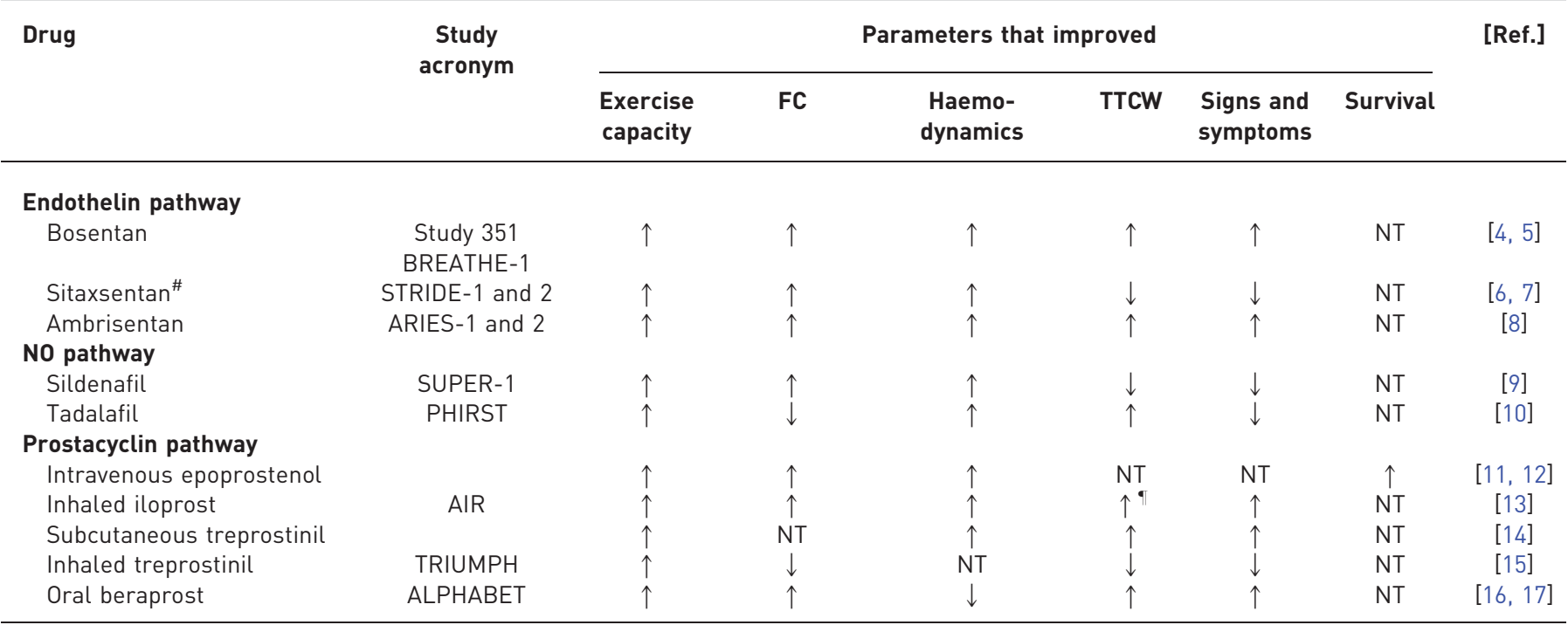

FC: functional class; TTCW: time to clinical worsening; NO: nitric oxide; NT: not tested; $\uparrow:$ parameter improved; $\downarrow$ : parameter did not improve. \#: withdrawn from market in 2010 due to two cases of fatal hepatic failure linked to its use; ": TTCW was defined as a combination of $\geqslant 10 \%$ improvement in walking distance combined with an absence of clinical deterioration.

Data from the large, multicentre, double-blind phase III SERAPHIN (Study with an Endothelin Receptor Antagonist in Pulmonary Arterial Hypertension to Improve Clinical Outcome) trial have recently been published [27]. SERAPHIN was an event-driven trial with a primary end-point of time to first morbidity or mortality event. Morbidity and mortality were chosen as a primary end-point to reflect recommendations from the 4th World Symposium on Pulmonary Hypertension [28], with the aim of providing robust, clinically meaningful data that is relevant to the long-term nature of PAH. In the SERAPHIN study, $10 \mathrm{mg}$ of macitentan significantly reduced the risk of morbidity and mortality by $45 \%(\mathrm{p}<0.001)$. Macitentan was well tolerated by the patients in this trial and, notably, adverse events commonly associated with the ERA drug class (elevated liver aminotransferases and peripheral oedema) occurred at a similar rate to patients who received placebo across all groups [27]. Macitentan has recently been approved by the US Food and Drug Administration for the treatment of PAH patients.

\section{Selexipag}

Selexipag is a highly selective oral IP receptor agonist that is rapidly hydrolysed to a long-acting metabolite [29]. Both selexipag and its active metabolite have a high binding affinity for the IP receptor and, unlike prostacyclin analogues, do not activate other prostanoid receptors. The selective nature of selexipag may translate into an improved safety profile, particularly with regards to gastrointestinal effects as, unlike iloprost and beraprost, selexipag and its metabolite do not stimulate gastric smooth muscle via the prostaglandin E (EP) receptors EP3 and EP1 [30].

In a phase II proof-of-concept study in 43 patients with symptomatic PAH receiving either ERA or PDE-5i therapy, selexipag significantly improved PVR compared with placebo (treatment effect, per protocol analysis, 30.3\%; $\mathrm{p}=0.0045$ ) (fig. 3) [31]. Selexipag-treated patients also experienced an increase in 6-min walk distance (6MWD) (mean change from baseline $24.7 \mathrm{~m}$ ) although this did not reach significance when compared with placebo. Selexipag was well tolerated at doses up to $800 \mathrm{mg}$ twice daily [31]. The encouraging preliminary results from this pilot study provided the rationale for investigating the effect of selexipag on morbidity and mortality in the event-driven phase III GRIPHON (Prostaglandin Receptor Agonist in Pulmonary Arterial Hypertension) study [32].

Oral drugs acting on the prostacyclin pathway, such as selexipag, are an attractive therapeutic proposition. Intravenous prostacyclin analogues are potent drugs but their invasive mode of administration is a major drawback to their utility and also acceptance by the patient. Although selexipag is the first oral IP receptor agonist investigated for $\mathrm{PAH}$, it is not the first oral drug to be developed for this pathway. Beraprost is an oral prostacyclin analogue that is already in clinical use. In clinical trials, beraprost was shown to have initial effects in improving exercise capacity [17] and reducing disease progression [16]; however, these effects 


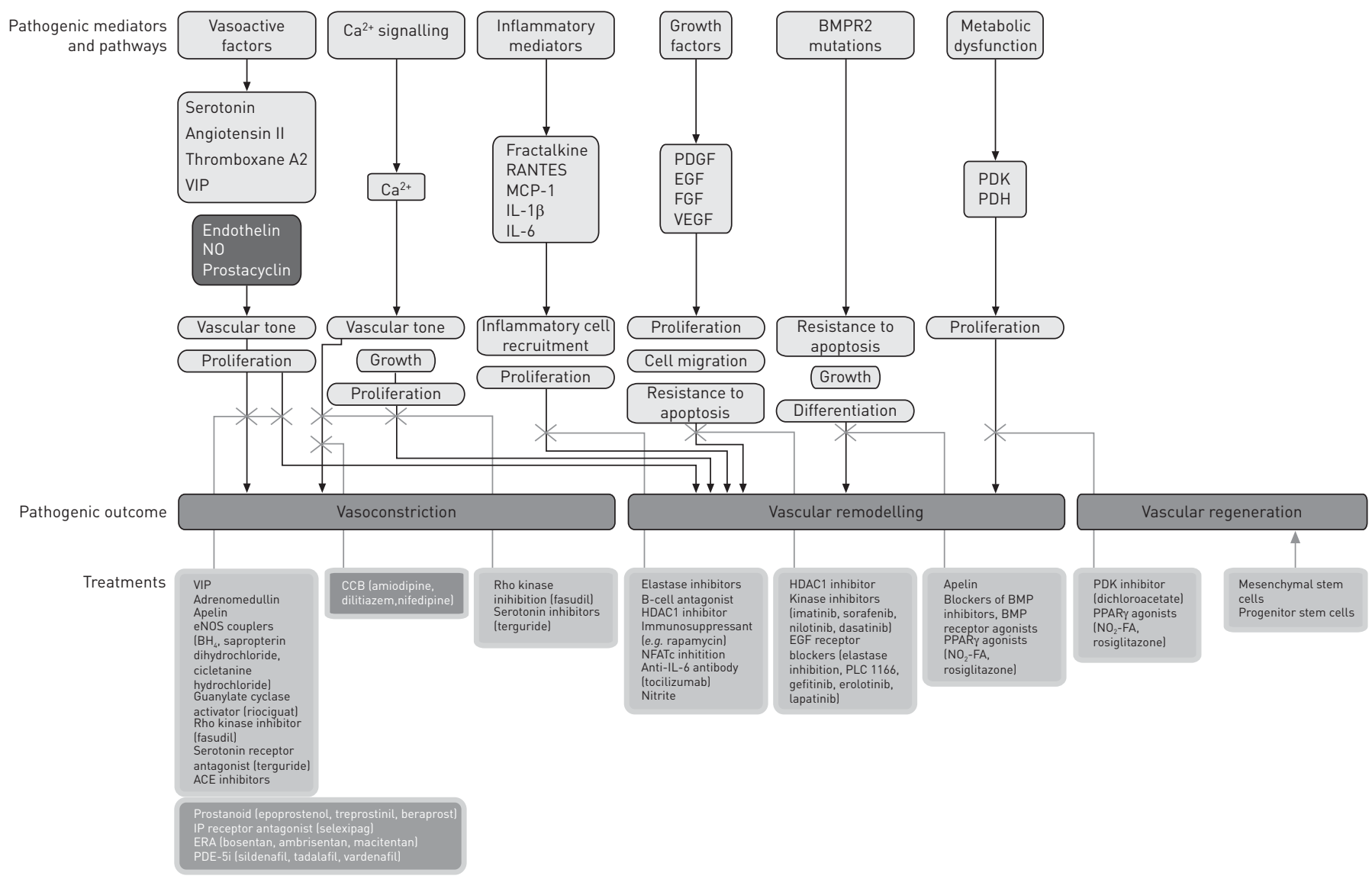

FIGURE 2 Compounds acting on pathogenic pathways of pulmonary arterial hypertension. BMPR2: bone morphogenetic peptide receptor 2; VIP: vasoactive intestinal peptide; NO: nitric oxide; RANTES: regulated on activation, normal T-cell expressed and secreted; MCP: monocyte chemoattractant protein; IL: interleukin; PDGF: platelet-derived growth factor; EGF: epidermal growth factor; FGF: fibroblast growth factor; VEGF: vascular epidermal growth factor; PDK: pyruvate dehydrogenase kinase; $\mathrm{PDH}$ : pyruvate dehydrogenase; eNOS: endothelial nitric oxide synthase; $\mathrm{BH}_{4}$ : tetrahydrobiopterin; ACE: angiotensin-converting enzyme; CCB: calcium channel blocker; HDAC: histone deacetylase; NFATc: nuclear factor of activated T-cells, cytoplasmic; PLC: phospholipase C; BMP: bone morphogenetic peptide; PPAR: peroxisome proliferator-activated receptor; $\mathrm{NO}_{2}$-FA: nitrated fatty acid; IP: prostaglandin receptor; ERA: endothelin receptor antagonist; PDE5-i: phosphodiesterase type-5 inhibitor.

were not sustainable over the longer term [33]. This lack of sustainability coupled with an adverse event profile typical of prostacyclin therapy means its risk-benefit profile is not ideal [16].

The efficacy of another oral prostacyclin analogue, treprostinil, was assessed in the FREEDOM-C trial. The addition of oral treprostinil therapy to background ERA or PDE-5i therapy failed to produce significant improvements in either 6MWD or Borg dyspnoea score [34]. It seems unlikely that oral treprostinil will be approved by the regulatory authorities.

\section{Riociguat}

Riociguat is a stimulator of soluble guanylate cyclase (sGC) that targets the NO pathway. Riociguat also sensitises sGC to NO and triggers downstream increases in cyclic guanosine monophosphate that will promote vasorelaxation [35].

In a phase II study in patients with functional class II/III PAH or CTEPH, treatment with riociguat for 12 weeks resulted in a significant increase in 6MWD and reductions in PVR [36]. Subsequently, riociguat has been evaluated in two large phase III trials: PATENT-1 (Pulmonary Arterial Hypertension sGC-stimulator Trial) in 445 treatment-experienced and -naïve patients with PAH [37] and CHEST-1 (Chronic Thromboembolic Pulmonary Hypertension sGC-Stimulator Trial) in 263 patients with inoperable CTEPH [38].

In PATENT-1, 12 weeks of treatment with riociguat was well tolerated and resulted in significant improvements in 6MWD (placebo-corrected improvement $35.8 \mathrm{~m} ; \mathrm{p}<0.001$ ), PVR ( $\mathrm{p}<0.001$ ), functional class $(p=0.003)$, time to clinical worsening $(p=0.005)$ and Borg dyspnoea score $(p=0.002)$ [37]. Interim data from the long-term extension study PATENT-2 have recently been reported: after 1 year of treatment, 
FIGURE 3 Change in pulmonary vascular resistance (PVR) from baseline to week 17 (per protocol analysis). Data are presented as geometric means and error bars represent 95\% confidence limits (CL). Baseline PVR values (mean \pm SD) for per protocol population for selexipag were 951.9 \pm $434.5 \mathrm{dyn} \cdot \mathrm{s}^{\cdot} \mathrm{cm}^{-5}$ and for placebo were $826.8 \pm 195.8 \mathrm{dyn} \cdot \mathrm{s} \cdot \mathrm{cm}^{-5}$. TE: treatment effect. Reproduced from [31].

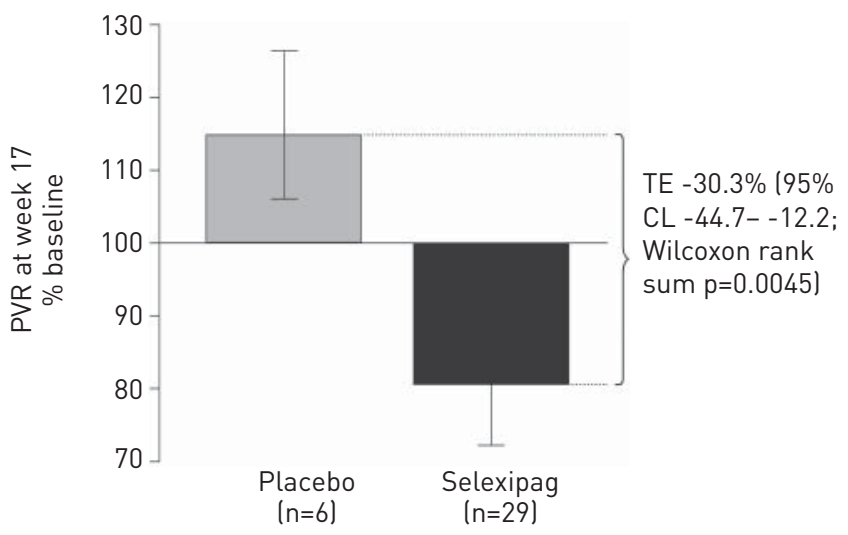

6MWD continued to improve with a mean increase in the overall cohort $(n=214)$ of $48 \pm 72 \mathrm{~m}$ compared with baseline [39]. Functional class also continued to improve and $68 \%$ of the overall cohort were in functional class I/II after 1 year of treatment (versus 38-49\% at baseline); 36\% and 57\% of patients showed improved or stable functional class, respectively. Riociguat has recently been approved by the US Food and Drug Administration for the treatment of PAH patients.

In CHEST-1, patients with CTEPH treated for 16 weeks showed a significant increase in 6MWD (46 m; $\mathrm{p}<0.001)$ and secondary end-points, including PVR $(\mathrm{p}<0.001)$, reductions in $\mathrm{N}$-terminal pro-brain natriuretic peptide (NT-proBNP; $p=0.001)$ and functional class $(p=0.003)$, compared with placebo [38]. Previously, there was little evidence that $\mathrm{PAH}$-specific therapies were useful in the treatment of patients with CTEPH. The BENEFIT (Bosentan Effects in Inoperable Forms Of Chronic Thromboembolic Pulmonary Hypertension) trial explored the efficacy of bosentan in the treatment of 157 patients with inoperable CTEPH and showed significant improvement in PVR versus placebo, but no significant improvement in 6MWD [40]. Riociguat has recently been approved by the US Food and Drug Administration for the treatment of inoperable CTEPH patients or operable CTEPH with recurrent $\mathrm{PH}$.

Imatinib

Imatinib is an anti-proliferative agent that was originally designed to inhibit the oncogenic Bcr-abl tyrosine kinase in patients with chronic myeloid leukaemia [41]. Imatinib also has an inhibitory effect on plateletderived growth factor and c-KIT signalling. These compounds are both important in vascular smooth muscle cell proliferation and hyperplasia and have been implicated in the development of PH [42-44].

Imatinib has been shown to reverse pulmonary vascular disease in animal models of PAH [45], and has been shown to have in vitro anti-proliferative and pro-apoptotic effects on pulmonary artery smooth muscle cells taken from patients with PAH [46].

An initial case study reported the effects of imatinib in a patient with PAH classified as New York Heart Association (NYHA) functional class IV, whose condition was deteriorating despite receiving combination therapy with oral bosentan, inhaled iloprost and sildenafil (but who refused intravenous prostacyclin therapy) [47]. Treatment with imatinib produced improvements in the patient's 6MWD and haemodynamics and the patient improved from NYHA functional class IV to II. This effect was sustained after 6 months of treatment [47].

In a 24-week, phase II study in 59 patients with PAH (functional class II-IV) and who had an inadequate response to previous therapy, patients were additionally treated with imatinib or placebo. Patients treated with imatinib showed a mean improvement of $22 \mathrm{~m}$ in $6 \mathrm{MWD}$ compared with a decline of $1 \mathrm{~m}$ in the placebo group, although this difference was not significant [48]. However, significant improvements were seen in PVR (imatinib $-300 \mathrm{dyn} \cdot \mathrm{s} \cdot \mathrm{cm}^{-5}$ versus placebo $-78 \mathrm{dyn} \cdot \mathrm{s} \cdot \mathrm{cm}^{-5} ; \mathrm{p}<0.01$ ) and cardiac output (imatinib $+0.6 \mathrm{~L} \cdot \mathrm{min}^{-1}$ versus placebo $-0.1 \mathrm{~L} \cdot \mathrm{min}^{-1} ; \mathrm{p}=0.02$ ).

In the recently reported phase III IMPRES (Imatinib in Pulmonary Arterial Hypertension, a Randomised, Efficacy Study) trial, imatinib used as add-on therapy significantly improved exercise capacity and haemodynamics in patients with advanced PAH. These advanced patients were symptomatic despite treatment with two or more PAH-specific therapies. However, imatinib did not provide a benefit in terms of functional class, time to clinical worsening or mortality [41]. 
There are concerns regarding the side-effect profile of imatinib in PAH. In the phase II trial, serious adverse events were reported in $39 \%$ of patients treated with imatinib versus $23 \%$ in the placebo group [48]. Both serious adverse events and discontinuations were more frequent with imatinib than placebo in the phase III trial (44\% versus 30\% and 33\% versus 18\%, respectively) [41]. Adverse events reported in the phase III trial were similar to those reported with the use of imatinib in other indications; however there was an unexpectedly high incidence of subdural haematoma patients receiving imatinib in addition to oral anticoagulants [41].

Other kinase inhibitors have been considered for the treatment of PAH. Of these, the most promising is nilotinib, a follow-on compound from imatinib. Rat models suggest that this may be a more efficacious treatment compared with imatinib [49], and the efficacy and safety of this treatment in PAH has recently been investigated [50]. The results have not yet been published. The more general kinase inhibitors sorafenib and dastinib have also been explored for the treatment of $\mathrm{PAH}$; however, due to safety concerns they are unlikely to undergo further development [51].

\section{New drugs in early phase of development}

As shown in figure 1, there are a number of new pathways implicated in vasoconstriction and/or remodelling of the vasculature that are key to the pathogenesis of PAH. These pathways have provided researchers with many new possible drug targets for the treatment of PAH. A number of compounds that target these pathways are being investigated preclinically and some of these have progressed into small studies with patients (fig. 2). A recent and extensive review article has been published outlining some of the more detailed mechanisms for these targets [52]. In this review, we will also discuss these new pathways according to their role in the pathogenesis of PAH and aim to provide a succinct overview and update.

\section{Vasoactive factors}

Vasoactive intestinal peptide

Vasoactive intestinal peptide (VIP) is a molecule that acts to relax the vasculature and reduce the effects of vasoconstrictors [53]. The importance of VIP in PAH was demonstrated in mutant mice models, where deletion of the VIP gene led to significant increases in right ventricular (RV) systolic pressures, vascular remodelling and inflammation [54]. In these VIP knockout mice, both the vascular and right ventricular remodelling were attenuated by treatment with VIP. Further experiments in rat models with monocrotaline-induced PAH suggested that treatment with VIP may be more effective than treatment with bosentan and that combination therapy with bosentan could potentially give a greater efficacy than either VIP or bosentan therapy alone [53].

In humans, a small study observing the effects of VIP in 20 patients with idiopathic PAH during right heart catheterisation demonstrated that a single dose of VIP temporarily improved haemodynamics [55]. The single-centre, open-label study of eight patients found that haemodynamics and 6MWD were improved following 3 months of treatment with VIP [56]. The multicentre phase II study in 56 patients suggested that there was no reduction in PVR or increase in exercise capacity over 12 weeks compared with placebo [57, 58]. It is not clear to date if there will be additional trials with VIP.

\section{Endothelial NO synthase couplers}

Endothelial NO is a well-known and established contributory factor to PAH and it is important in the regulation of vascular tone. The production of endothelial NO is dependent on endothelial NO synthase (eNOS). An increased understanding of this enzyme has found that eNOS must be dimerised, or coupled, in order to produce NO and to cease production of vasoconstrictors such as superoxide [59]. Because eNOS can produce both vasorelaxant and vasoconstrictive molecules, the coupling of eNOS has a two-fold impact on the balance of vasoactive factors released in the endothelium.

The efficacy of the eNOS coupling molecule, the eNOS co-factor sapropterin dihydrochloride, with $\mathrm{PH}$ has been assessed in the treatment of patients [60]. The small study of 18 patients monitored markers of NO synthesis, inflammation, exercise capacity and cardiac function [60]. Although NO synthesis did not appear to increase following treatment with sapropterin dihydrochloride, there were significant $(p=0.002)$ improvements in exercise capacity and the treatment was well tolerated, indicating this is a treatment that may warrant further study.

\section{Rho kinases}

Rho kinases mediate vasoconstriction and endothelial dysfunction; two key components of PAH [61]. The rho-kinase pathway causes downstream changes to intracellular calcium and causes calcium sensitisation. 
Changes in response to and levels of intracellular calcium are important as intracellular calcium signalling is involved in vasoconstriction and pulmonary arterial smooth muscle cell proliferation [62].

The rho-kinase inhibitor fasudil has shown promising results in the treatment of PAH in monocrotalineinduced rat models, even when compared to the licensed treatments bosentan and sildenafil [63].

In a small cohort of 15 patients with $\mathrm{PAH}$, exposure to fasudil during right heart catheterisation produced significant $(\mathrm{p}<0.05)$ decreases in mean pulmonary arterial pressures and tended to decrease PVR, although it did not affect cardiac output [64]. This study tested the same parameters following exposure to NO and found similar results, suggesting that fasudil might produce similar results to treatment with NO.

\section{Serotonin}

Serotonin is an important vasoactive and mitogenic compound that is synthesised by the endothelial cells and acts on pulmonary arterial smooth muscle cells [65]. The serotonin transporter is required for serotonin to elicit its mitogenic effects and transgenic mice overexpressing the serotonin transporter have been shown to spontaneously develop PH [66].

Chronic administration of the serotonin receptor antagonist terguride has been shown to dose-dependently prevent the development and progression of monocrotaline-induced PAH in rats [67]. A 16-week study investigated the effect of terguride on PVR, 6MWD, haemodynamics, NT-proBNP and time to clinical worsening in 78 patients with PAH [68]. Although there were no overall significant improvements in PVR or the other end-points investigated, subgroup analysis found that PVR significantly improved in patients who were also treated with an ERA [68]. Terguride is already marketed in Japan for the treatment of hyperprolactinaemia and, as such, has already passed some of the stages and testing that are required for a treatment to be approved.

Apelin

Apelin is a peptide that is thought to play a role in angiogenesis, and regulate endothelial and smooth muscle cell apoptosis and proliferation, and has wider effects by altering eNOS expression [69]. Patients with PAH typically have lower levels of apelin.

Reduced or altered expression of BMPR2 has been linked to PAH [70]. Disruption of BMPR2 signalling via the peroxisome proliferator-activated receptor (PPAR) $\gamma / \beta$-catenin complex was found to reduce levels of apelin promoting pulmonary arterial smooth muscle cell proliferation and reduce endothelial cell apoptosis [71].

Results from animal models show that apelin elicits a vasodilatory effect $[72,73]$ and can reduce pulmonary arterial pressures [73]. Chronic administration in animal models also shows a pressure-reducing effect that may be due to a stabilising effect of apelin on the endothelial cells [71, 74].

As apelin is a peptide, some of the key challenges to the use of apelin in the treatment of PAH are its short half-life, developing an appropriate mode of administration, and managing the systemic vasodilatory effect of apelin [69].

\section{Inflammatory mediators \\ Immunosuppressants}

The prevalence of PAH in patients with autoimmune diseases such as systemic sclerosis and HIV have long indicated a link between immunity and PAH. Preclinical studies have shown that levels of pleiotropic cytokines such as interleukin (IL)-6 and IL-1 $\beta$, which have roles in immune regulation, haematopoiesis and inflammation, are increased in patients with PAH $[65,75]$. Further to this, a case report of a patient with Castleman's-related PAH showed that treatment of the patient with the anti-IL-6 monoclonal antibody tocilizumab was effective [75]. Tocilizumab is currently licensed for the treatment of rheumatoid arthritis and is also licensed for the treatment of Castleman's disease in Japan. As tocilizumab is already in clinical use, its safety profile in patients without PAH is well established, and the preclinical and case study data suggest this may be an interesting therapeutic option for patients with some forms of PAH, perhaps related to autoimmunity.

Another immunosuppressant that has been investigated in animal models of PAH is rapamycin. Rapamycin is a potent anti-proliferative agent that has been shown to prevent the RV wall thickening and increased proliferation of pulmonary vasculature that leads to the development of PAH in hypoxic mice [76]. In addition, rapamycin also reversed pulmonary vascular remodelling in mice that were allowed to develop hypoxia-induced PAH. Therefore, both these immunosuppressants, rapamycin and tocilizumab, may provide a novel therapeutic strategy for PAH [76]. 


\section{Growth factors}

Epidermal growth factor receptor blockers

Epidermal growth factor (EGF) has been shown to increase pulmonary arterial smooth muscle cell proliferation that can contribute to the vascular remodelling, which is, in part, causative of PAH [77]. Serine elastases act to break down extracellular matrix and this can lead to the release of EGF. In mouse models of monocrotaline-induced $\mathrm{PAH}$, the use of serine elastase inhibitors has been shown to reverse the monocrotaline-induced PAH [78].

In rats with monocrotaline-induced $\mathrm{PAH}$, the EGF receptor inhibitors gefitinib, erlotinib and lapatinib were shown to inhibit EGF-induced smooth muscle cell proliferation of the pulmonary vasculature [77]. However, at their highest tolerated dose, there was no significant improvement in RV systolic pressure or hypertrophy observed. Furthermore, no upregulation of EGF receptors was observed in lung tissue of patients with idiopathic PAH [77], suggesting that EGF receptor antagonists may not be as promising for the treatment of $\mathrm{PAH}$ as was originally thought.

Nevertheless, the results from the experiments with the serine elastase inhibitors show that targeting the EGF pathway might still be an effective treatment strategy for PAH and that this is an area that requires further investigation.

\section{BMPR2 mutation}

\section{PPAR $\gamma$ agonists}

PPAR $\gamma$ is a transcription factor that appears to be important in pulmonary arterial smooth muscle cell proliferation. Mutant mice with the PPAR $\gamma$ gene knocked out of either the endothelial or smooth muscle cells have been shown to develop PAH $[79,80]$.

As previously mentioned, BMPR2 mutations can be causative of PAH and are responsible for many cases of seemingly idiopathic PAH [70]. PPAR $\gamma$ is a downstream target of BMPR2 signalling and on formation of a complex with $\beta$-catenin appears to trigger the transcription on apelin (the importance of which was described previously) [71].

Treatment of rats with experimental PAH using the PPAR $\gamma$ agonist rosiglitazone attenuated the development of hypoxia-induced $\mathrm{PAH}$ [81]. When compared with hypoxic rats not treated with rosiglitazone or normal rats, the expression of the markers endothelin and vascular endothelial growth factor was similar in the rosiglitazone-treated and normal mice; they had deteriorated in the hypoxic, nontreated rats [81].

A recent study explored the vasodilatory effects of PPAR $\gamma$ antagonists in human pulmonary arteries taken from patients without PAH during resection of lung carcinoma. This study found that the PPAR $\gamma$ antagonists pioglitazone and rosiglitazone act to relax human pulmonary arteries, and that rosiglitazone was the most potent vasodilator [82]. These results further suggest that PPAR $\gamma$ antagonists may also be a novel therapeutic route for the treatment of PAH.

\section{Mitochondrial dysfunction}

\section{Dichloroacetate}

In healthy people, adenosine triphosphate (ATP) is produced by the Krebs cycle; however, evidence has shown that when a patient with PAH experiences RV hypertrophy, ATP production is increasingly driven by the less efficient process of glycolysis $[83,84]$. It has been hypothesised that the shift to increased glycolysis could, in part, be caused by activation of pyruvate dehydrogenase kinase (PDK). This prevents pyruvate from entering the Krebs cycle so that energy must then be generated via glycolysis [83]. The PDK inhibitor dichloroacetate has been shown to decrease proliferation and increase apoptosis of pulmonary arterial smooth muscle cells from monocrotaline-induced mice models of $\mathrm{PAH}$, as well as reducing growth in pulmonary arterial smooth muscle cells from patients with idiopathic PAH [85]. Further studies in rat models of PAH found that dichloroacetate increased glucose uptake and, with chronic therapy, improved cardiac output [86].

As stimulation of serotonin receptors in pulmonary arterial smooth muscle cells has been shown to decrease apoptosis and activate the PDK pathway, it is possible that the serotonin inhibitor terguride, described earlier in this review, may also act, at least in part, via a PDK pathway [87].

\section{Endothelial progenitor stem cells and mesenchymal stromal cells}

Endothelial progenitor cells (EPCs) originate in the bone marrow and are thought to migrate to sites of vascular injury and differentiate into endothelial cells in order to repair the damaged tissue [88]. In patients with PAH, the levels of circulating EPCs are altered and EPCs may also be dysfunctional [89-91]. 
Transplantation of EPCs in mouse models of monocrotaline-induced PAH has been shown to prevent the development of PAH [92].

A small, randomised controlled trial was conducted over 12 weeks in patients with idiopathic PAH, where 16 patients were treated with conventional therapy and 15 patients additionally received an intravenous infusion of EPCs [93]. At the end of this preliminary study, 6MWD was significantly $(p<0.0001)$ improved in the EPC-treated patients, as were mean pulmonary arterial pressure, PVR and cardiac output. There were no serious adverse events in the EPC group.

An alternative to EPCs are mesenchymal stromal cells (MSCs). MSCs are adult stem cells that are also derived from the bone marrow. MSCs have the advantage that they can be prepared in batches to be used when needed, as with chemical-based therapies [92]. To date, MSCs have only been tested in rat models of monocrotaline-induced PAH. However, various studies have shown that MSCs will have a beneficial effect in rats with monocrotaline-induced $\mathrm{PAH}$ suggesting that these may provide an efficacious and more convenient therapy for PAH [92].

\section{Conclusions}

Currently available $\mathrm{PAH}$-specific therapies have improved outcomes in $\mathrm{PAH}$, but the disease remains progressive and ultimately fatal. In light of an increasing understanding of the pathogenesis of the disease, a number of new drugs are in clinical and preclinical development. These not only act on established pathways involved in the regulation of pulmonary vascular tone by the endothelium, but also on new pathways implicated in pulmonary vascular remodelling. In addition, changes in the way clinical trials are performed in $\mathrm{PAH}$, with the move towards long-term, event-driven studies, will provide more robust and clinically relevant data. This should strengthen the basis upon which physicians will judge if and when to use new treatments.

\section{Acknowledgements}

Medical writing support was provided by R. Doyle (Elements Communications Ltd, Westerham, UK) funded by Actelion Pharmaceuticals Ltd (Allschwil, Switzerland).

\section{References}

1 Humbert M, Sitbon O, Simonneau G. Treatment of pulmonary arterial hypertension. N Engl J Med 2004; 351: $1425-1436$.

2 Voelkel NF, Gomez-Arroyo J, Abbate A, et al. Pathobiology of pulmonary arterial hypertension and right ventricular failure. Eur Respir J 2012; 40: 1555-1565.

3 Sitbon O, Morrell N. Pathways in pulmonary arterial hypertension: the future is here. Eur Respir Rev 2012; 21: 321-327.

4 Channick RN, Simonneau G, Sitbon O, et al. Effects of the dual endothelin-receptor antagonist bosentan in patients with pulmonary hypertension: a randomised placebo-controlled study. Lancet 2001; 358: 1119-1123.

5 Rubin LJ, Badesch DB, Barst RJ, et al. Bosentan therapy for pulmonary arterial hypertension. N Engl J Med 2002; 346: 896-903.

6 Barst RJ, Langleben D, Frost A, et al. Sitaxsentan therapy for pulmonary arterial hypertension. Am J Respir Crit Care Med 2004; 169: 441-447.

7 Barst RJ, Langleben D, Badesch D, et al. Treatment of pulmonary arterial hypertension with the selective endothelin-A receptor antagonist sitaxsentan. J Am Coll Cardiol 2006; 47: 2049-2056.

8 Galiè N, Olschewski H, Oudiz RJ, et al. Ambrisentan for the treatment of pulmonary arterial hypertension: results of the ambrisentan in pulmonary arterial hypertension, randomized, double-blind, placebo-controlled, multicenter, efficacy (ARIES) study 1 and 2. Circulation 2008; 117: 3010-3019.

9 Galiè N, Ghofrani HA, Torbicki A, et al. Sildenafil citrate therapy for pulmonary arterial hypertension. $N$ Engl J Med 2005; 353: 2148-2157.

10 Galiè N, Brundage BH, Ghofrani HA, et al. Tadalafil therapy for pulmonary arterial hypertension. Circulation 2009; 119: 2894-2903.

11 Rubin LJ, Mendoza J, Hood M, et al. Treatment of primary pulmonary hypertension with continuous intravenous prostacyclin (epoprostenol). Results of a randomized trial. Ann Intern Med 1990; 112: 485-491.

12 Barst RJ, Rubin LJ, Long WA, et al. A comparison of continuous intravenous epoprostenol (prostacyclin) with conventional therapy for primary pulmonary hypertension. The Primary Pulmonary Hypertension Study Group. N Engl J Med 1996; 334: 296-302.

13 Olschewski H, Simonneau G, Galie N, et al. Inhaled iloprost for severe pulmonary hypertension. N Engl J Med 2002; 347: 322-329.

14 Simonneau G, Barst RJ, Galiè N, et al. Continuous subcutaneous infusion of treprostinil, a prostacyclin analogue, in patients with pulmonary arterial hypertension: a double-blind, randomized, placebo-controlled trial. Am J Respir Crit Care Med 2002; 165: 800-804.

15 McLaughlin VV, Benza RL, Rubin LJ, et al. Addition of inhaled treprostinil to oral therapy for pulmonary arterial hypertension: a randomized controlled clinical trial. J Am Coll Cardiol 2010; 55: 1915-1922.

16 Barst RJ, McGoon M, McLaughlin V, et al. Beraprost therapy for pulmonary arterial hypertension. J Am Coll Cardiol 2003; 41: 2119-2125. 
Galiè N, Humbert M, Vachiery JL, et al. Effects of beraprost sodium, an oral prostacyclin analogue, in patients with pulmonary arterial hypertension: a randomized, double-blind, placebo-controlled trial. J Am Coll Cardiol 2002; 39: 1496-1502.

18 Humbert M, Sitbon O, Chaouat A, et al. Survival in patients with idiopathic, familial, and anorexigen-associated pulmonary arterial hypertension in the modern management era. Circulation 2010; 122: 156-163.

19 Ling Y, Johnson MK, Kiely DG, et al. Changing demographics, epidemiology, and survival of incident pulmonary arterial hypertension: results from the pulmonary hypertension registry of the United Kingdom and Ireland. Am J Respir Crit Care Med 2012; 186: 790-796.

20 Benza RL, Miller DP, Barst RJ, et al. An evaluation of long-term survival from time of diagnosis in pulmonary arterial hypertension from the REVEAL Registry. Chest 2012; 142: 448-456.

21 Gatfield J, Grandjean CM, Sasse T, et al. Slow receptor dissociation kinetics differentiate macitentan from other endothelin receptor antagonists in pulmonary arterial smooth muscle cells. PLoS One 2012; 7: e47662.

22 Iglarz M, Binkert C, Morrison K, et al. Pharmacology of macitentan, an orally active tissue-targeting dual endothelin receptor antagonist. J Pharmacol Exp Ther 2008; 327: 736-745.

23 Atsmon J, Dingemanse J, Shaikevich D, et al. Investigation of the effects of ketoconazole on the pharmacokinetics of macitentan, a novel dual endothelin receptor antagonist, in healthy subjects. Clin Pharmacokinet 2013; 52: 685-692.

24 Bruderer S, Aanismaa P, Homery MC, et al. Effect of cyclosporine and rifampin on the pharmacokinetics of macitentan, a tissue-targeting dual endothelin receptor antagonist. AAPS J 2012; 14: 68-78.

25 Bolli $\mathrm{MH}$, Boss $\mathrm{C}$, Binkert C, et al. The discovery of N-[5-(4-Bromophenyl)-6-[2-[(5-bromo-2pyrimidinyl)oxy] ethoxy]-4-pyrimidinyl]-N'-propylsulfamide (macitentan), an orally active, potent dual endothelin receptor antagonist. J Med Chem 2012; 55: 7849-7861.

26 Raja SG. Macitentan, a tissue-targeting endothelin receptor antagonist for the potential oral treatment of pulmonary arterial hypertension and idiopathic pulmonary fibrosis. Curr Opin Investig Drugs 2010; 11: 1066-1073.

27 Pulido T, Adzerikho I, Channick RN, et al. Macitentan and morbidity and mortality in pulmonary arterial hypertension. N Engl J Med 2013; 369: 809-818.

28 McLaughlin VV, Badesch DB, Delcroix M, et al. End points and clinical trial design in pulmonary arterial hypertension. J Am Coll Cardiol 2009; 54: Suppl. 1, S97-S107.

29 Kuwano K, Hashino A, Asaki T, et al. 2-[4-[(5,6-diphenylpyrazin-2-yl)(isopropyl)amino]butoxy]-N-(methylsulfonyl)acetamide (NS-304), an orally available and long-acting prostacyclin receptor agonist prodrug. J Pharmacol Exp Ther 2007; 322: 1181-1188.

30 Morrison K, Studer R, Ernst R, et al. Differential effects of selexipag [corrected] and prostacyclin analogs in rat pulmonary artery. J Pharmacol Exp Ther 2012; 343: 547-555.

31 Simonneau G, Torbicki A, Hoeper MM, et al. Selexipag: an oral, selective prostacyclin receptor agonist for the treatment of pulmonary arterial hypertension. Eur Respir J 2012; 40: 874-880.

32 Clinicaltrials.gov. Selexipag (ACT-293987) in pulmonary arterial hypertension, GRIPHON Trial. NCT01106014. http://clinicaltrials.gov/ct2/show/NCT01106014?term=GRIPHON\&rank=1 Date last accessed: August 28, 2013. Date last updated: September 3, 2013.

33 Barst RJ, McGoon M, McLaughlin V, et al. Beraprost therapy for pulmonary arterial hypertension. J Am Coll Cardiol 2003; 41: 2119-2125.

34 Tapson VF, Torres F, Kermeen F, et al. Oral treprostinil for the treatment of pulmonary arterial hypertension in patients on background endothelin receptor antagonist and/or phosphodiesterase type 5 inhibitor therapy (the FREEDOM-C study): a randomized controlled trial. Chest 2012; 142: 1383-1390.

35 Schermuly RT, Janssen W, Weissmann N, et al. Riociguat for the treatment of pulmonary hypertension. Expert Opin Investig Drugs 2011; 20: 567-576.

36 Ghofrani HA, Hoeper MM, Halank M, et al. Riociguat for chronic thromboembolic pulmonary hypertension and pulmonary arterial hypertension: a phase II study. Eur Respir J 2010; 36: 792-799.

37 Ghofrani HA, Galie N, Grimminger F, et al. Riociguat for the treatment of pulmonary arterial hypertension. $N$ Engl J Med 2013; 369: 330-340.

38 Ghofrani HA, D'Armini AM, Grimminger F, et al. Riociguat for the treatment of chronic thromboembolic pulmonary hypertension. N Engl J Med 2013; 369: 319-329.

39 Lewis JR, Nazzareno G, Friedrich G, et al. Riociguat for the treatment of pulmonary arterial hypertension (PAH): a phase III long-term extension study (PATENT-2). Am J Respir Crit Care Med 2013; 187: A3531.

40 Jais X, D'Armini AM, Jansa P, et al. Bosentan for treatment of inoperable chronic thromboembolic pulmonary hypertension: BENEFiT (Bosentan Effects in iNopErable Forms of chronIc Thromboembolic pulmonary hypertension), a randomized, placebo-controlled trial. J Am Coll Cardiol 2008; 52: 2127-2134.

41 Hoeper MM, Barst RJ, Bourge RC, et al. Imatinib mesylate as add-on therapy for pulmonary arterial hypertension: results of the randomized IMPRES study. Circulation 2013; 127: 1128-1138.

42 Humbert M, Monti G, Fartoukh M, et al. Platelet-derived growth factor expression in primary pulmonary hypertension: comparison of HIV seropositive and HIV seronegative patients. Eur Respir J 1998; 11: 554-559.

43 Montani D, Perros F, Gambaryan N, et al. C-kit-positive cells accumulate in remodeled vessels of idiopathic pulmonary arterial hypertension. Am J Respir Crit Care Med 2011; 184: 116-123.

44 Perros F, Montani D, Dorfmuller P, et al. Platelet-derived growth factor expression and function in idiopathic pulmonary arterial hypertension. Am J Respir Crit Care Med 2008; 178: 81-88.

45 Schermuly RT, Dony E, Ghofrani HA, et al. Reversal of experimental pulmonary hypertension by PDGF inhibition. J Clin Invest 2005; 115: 2811-2821.

46 Nakamura K, Akagi S, Ogawa A, et al. Pro-apoptotic effects of imatinib on PDGF-stimulated pulmonary artery smooth muscle cells from patients with idiopathic pulmonary arterial hypertension. Int J Cardiol 2012; 159: $100-106$.

47 Ghofrani HA, Seeger W, Grimminger F. Imatinib for the treatment of pulmonary arterial hypertension. $N$ Engl $J$ Med 2005; 353: 1412-1413.

48 Ghofrani HA, Morrell NW, Hoeper MM, et al. Imatinib in pulmonary arterial hypertension patients with inadequate response to established therapy. Am J Respir Crit Care Med 2010; 182: 1171-1177.

49 Nicholas D, Olivier B, Martin H, et al. Comparison of effects of imatinib and nilotinib in a rodent model of pulmonary arterial hypertension. Am J Respir Crit Care Med 2010; 181: A6304. 
50 Clinicaltrials.gov. Efficacy, safety, tolerability and pharmacokinetics (PK) of nilotinib (AMN107) in pulmonary arterial hypertension (PAH). NCT01179737 http://clinicaltrials.gov/ct2/show/NCT01179737?term $=$ NCT01179737\&rank $=1$ Date last accessed: August 30, 2013. Date last updated: March 25, 2013.

51 Chen MH, Kerkela R, Force T. Mechanisms of cardiac dysfunction associated with tyrosine kinase inhibitor cancer therapeutics. Circulation 2008; 118: 84-95.

52 Morrell NW, Archer SL, Defelice A, et al. Anticipated classes of new medications and molecular targets for pulmonary arterial hypertension. Pulm Circ 2013; 3: 226-244.

53 Hamidi SA, Lin RZ, Szema AM, et al. VIP and endothelin receptor antagonist: an effective combination against experimental pulmonary arterial hypertension. Respir Res 2011; 12: 141.

54 Stenmark KR, Meyrick B, Galie N, et al. Animal models of pulmonary arterial hypertension: the hope for etiological discovery and pharmacological cure. Am J Physiol Lung Cell Mol Physiol 2009; 297: L1013-L1032.

55 Leuchte $\mathrm{HH}$, Baezner $\mathrm{C}$, Baumgartner RA, et al. Inhalation of vasoactive intestinal peptide in pulmonary hypertension. Eur Respir J 2008; 32: 1289-1294.

56 Petkov V, Mosgoeller W, Ziesche R, et al. Vasoactive intestinal peptide as a new drug for treatment of primary pulmonary hypertension. J Clin Invest 2003; 111: 1339-1346.

57 Galiè N, Boonstra A, Ewert R, et al. Effects of inhaled aviptadil (vasoactive intestinal peptide) in patients with pulmonary arterial hypertension (PAH). Am J Respir Crit Care Med 2010; 181: A2516.

58 Said SI. Vasoactive intestinal peptide in pulmonary arterial hypertension. Am J Respir Crit Care Med 2012; 185: 786.

59 Kar S, Kavdia M. Modeling of biopterin-dependent pathways of eNOS for nitric oxide and superoxide production. Free Radic Biol Med 2011; 51: 1411-1427.

60 Robbins IM, Hemnes AR, Gibbs JS, et al. Safety of sapropterin dihydrochloride (6r-bh4) in patients with pulmonary hypertension. Exp Lung Res 2011; 37: 26-34.

61 Schwenke DO, Pearson JT, Sonobe T, et al. Role of Rho-kinase signaling and endothelial dysfunction in modulating blood flow distribution in pulmonary hypertension. J Appl Physiol 2011; 110: 901-908.

62 Kuhr FK, Smith KA, Song MY, et al. New mechanisms of pulmonary arterial hypertension: role of $\mathrm{Ca}^{2+}$ signaling. Am J Physiol Heart Circ Physiol 2012; 302: H1546-H1562.

63 Mouchaers KT, Schalij I, de Boer MA, et al. Fasudil reduces monocrotaline-induced pulmonary arterial hypertension: comparison with bosentan and sildenafil. Eur Respir J 2010; 36: 800-807.

64 Fujita H, Fukumoto Y, Saji K, et al. Acute vasodilator effects of inhaled fasudil, a specific Rho-kinase inhibitor, in patients with pulmonary arterial hypertension. Heart Vessels 2010; 25: 144-149.

65 El CH, Hassoun PM. Immune and inflammatory mechanisms in pulmonary arterial hypertension. Prog Cardiovasc Dis 2012; 55: 218-228.

66 MacLean MR, Deuchar GA, Hicks MN, et al. Overexpression of the 5-hydroxytryptamine transporter gene: effect on pulmonary hemodynamics and hypoxia-induced pulmonary hypertension. Circulation 2004; 109: 2150-2155.

67 Dumitrascu R, Kulcke C, Konigshoff $\mathrm{M}$, et al. Terguride ameliorates monocrotaline-induced pulmonary hypertension in rats. Eur Respir J 2011; 37: 1104-1118.

68 Ghofrani HA, Al-Hiti H, Vonk Noordegraaf A, et al. Proof-of-concept study to investigate the efficacy, hemodynamics and tolerability of terguride $v s$. placebo in subjects with pulmonary arterial hypertension: results of a double blind, randomised, prospective phase IIa study. Am J Respir Crit Care Med 2012; 185: A2496.

69 Andersen CU, Hilberg O, Mellemkjaer S, et al. Apelin and pulmonary hypertension. Pulm Circ 2011; 1: 334-346.

70 Rabinovitch M. Molecular pathogenesis of pulmonary arterial hypertension. J Clin Invest 2012; 122: 4306-4313.

71 Alastalo TP, Li M, Perez VJ, et al. Disruption of PPAR $\gamma / \beta$-catenin-mediated regulation of apelin impairs BMPinduced mouse and human pulmonary arterial EC survival. J Clin Invest 2011; 121: 3735-3746.

72 Huang P, Fan XF, Pan LX, et al. [Effect of apelin on vasodilatation of isolated pulmonary arteries in rats is concerned with the nitric oxide pathway]. Zhongguo Ying Yong Sheng Li Xue Za Zhi 2011; 27: 1-5.

73 Feng JH, Li WM, Wu XP, et al. Hemodynamic effect of apelin in a canine model of acute pulmonary thromboembolism. Peptides 2010; 31: 1772-1778.

74 Falcao-Pires I, Goncalves N, Henriques-Coelho T, et al. Apelin decreases myocardial injury and improves right ventricular function in monocrotaline-induced pulmonary hypertension. Am J Physiol Heart Circ Physiol 2009; 296: H2007-H2014.

75 Furuya Y, Satoh T, Kuwana M. Interleukin-6 as a potential therapeutic target for pulmonary arterial hypertension. Int J Rheumatol 2010; 2010: 720305.

76 Paddenberg R, Stieger P, von Lilien AL, et al. Rapamycin attenuates hypoxia-induced pulmonary vascular remodeling and right ventricular hypertrophy in mice. Respir Res 2007; 8: 15.

77 Dahal BK, Cornitescu T, Tretyn A, et al. Role of epidermal growth factor inhibition in experimental pulmonary hypertension. Am J Respir Crit Care Med 2010; 181: 158-167.

78 Cowan KN, Jones PL, Rabinovitch M. Elastase and matrix metalloproteinase inhibitors induce regression, and tenascin-C antisense prevents progression, of vascular disease. J Clin Invest 2000; 105: 21-34.

79 Hansmann G, de Jesus Perez VA, Alastalo TP, et al. An antiproliferative BMP-2/PPAR $\gamma /$ apoE axis in human and murine SMCs and its role in pulmonary hypertension. J Clin Invest 2008; 118: 1846-1857.

80 Guignabert C, Alvira CM, Alastalo TP, et al. Tie2-mediated loss of peroxisome proliferator-activated receptorgamma in mice causes PDGF receptor- $\beta$-dependent pulmonary arterial muscularization. Am J Physiol Lung Cell Mol Physiol 2009; 297: L1082-L1090.

81 Kim EK, Lee JH, Oh YM, et al. Rosiglitazone attenuates hypoxia-induced pulmonary arterial hypertension in rats. Respirology 2010; 15: 659-668.

82 Kozlowska H, Baranowska-Kuczko M, Schlicker E, et al. Relaxation of human pulmonary arteries by PPAR $\gamma$ agonists. Naunyn Schmiedebergs Arch Pharmacol 2013; 386: 445-453.

83 Piao L, Marsboom G, Archer SL. Mitochondrial metabolic adaptation in right ventricular hypertrophy and failure. J Mol Med (Berl) 2010; 88: 1011-1020.

84 Marsboom G, Wietholt C, Haney CR, et al. Lung ${ }^{18} \mathrm{~F}$-fluorodeoxyglucose positron emission tomography for diagnosis and monitoring of pulmonary arterial hypertension. Am J Respir Crit Care Med 2012; 185: 670-679.

85 Guignabert $\mathrm{C}, \mathrm{Tu} \mathrm{L}$, Izikki $\mathrm{M}$, et al. Dichloroacetate treatment partially regresses established pulmonary hypertension in mice with SM22 $\alpha$-targeted overexpression of the serotonin transporter. FASEB J 2009; 23: $4135-4147$. 
Piao L, Fang YH, Cadete VJ, et al. The inhibition of pyruvate dehydrogenase kinase improves impaired cardiac function and electrical remodeling in two models of right ventricular hypertrophy: resuscitating the hibernating right ventricle. J Mol Med (Berl) 2010; 88: 47-60.

87 Liu Y, Tian H, Yan X, et al. Serotonin inhibits apoptosis of pulmonary artery smooth muscle cells through 5-HT2A receptors involved in the pulmonary artery remodeling of pulmonary artery hypertension. Exp Lung Res 2013; 39: 70-79.

88 Asahara T, Murohara T, Sullivan A, et al. Isolation of putative progenitor endothelial cells for angiogenesis. Science 1997; 275: 964-967.

89 Diller GP, van Eijl S, Okonko DO, et al. Circulating endothelial progenitor cells in patients with Eisenmenger syndrome and idiopathic pulmonary arterial hypertension. Circulation 2008; 117: 3020-3030.

90 Junhui Z, Xingxiang W, Guosheng F, et al. Reduced number and activity of circulating endothelial progenitor cells in patients with idiopathic pulmonary arterial hypertension. Respir Med 2008; 102: 1073-1079.

91 Asosingh K, Aldred MA, Vasanji A, et al. Circulating angiogenic precursors in idiopathic pulmonary arterial hypertension. Am J Pathol 2008; 172: 615-627.

92 Suen C, Mei S, Stewart DJ. Cell therapy for pulmonary arterial hypertension: potential efficacy of endothelial progenitor cells and mesenchymal stem cells. Adv Pulm Hyperten J 2012; 11: 33-38.

93 Wang XX, Zhang FR, Shang YP, et al. Transplantation of autologous endothelial progenitor cells may be beneficial in patients with idiopathic pulmonary arterial hypertension: a pilot randomized controlled trial. J Am Coll Cardiol 2007; 49: 1566-1571. 